Nuclear accident casts a long shadow

EVIDENCE that last March's accident at the Three Mile Island nuclear power plant has already cast a long shadow over public attitudes towards a broad range of activities assosicated with nuclear power was presented by various speakers to last week's meeting of the American Association for the Advancement of Science.

Speaking at a session on risk in technological society, Dr Peterson, until recently director of the US Congress' Office of Technology Assessment and a member of the public commission established by President Carter to report on the accident, said that in the climate following the accident, public reaction to any incident involving a major release of radioactivity into the environment would almost certainly lead to demands for an end to the use of nuclear energy. "If in the interim we have tied our way of life to electricity from nuclear, the economic and social costs will be major indeed," he warned.

Dr Peterson drew attention to recent recommendations that plans for evacuating the residents close to a nuclear plant be developed before a plant is authorised to operate. Several nuclear physicists with the Nuclear Regulatory Commission, for example, had recently said that in the event of a future nuclear plant accident - and given the same amount of information as was available at the TMI incident - they would again recommend evacuation.

"Together these facts demonstrate that when individuals have the opportunity to dig deeply into the operation of nuclear power plants, they conclude that it is only a matter of time before an accident releasing a devastating amount of radioactive material occurs. Why else would we need evacuation plans?"' he asked.

Dr Peterson suggested that although the potential for a catastrophic accident raised the most amount of public concern, a more serious risk in the long run could come from the cumulative impact of countless minor releases of radioactivity. These ranged from uranium mill tailings, through the disposal of radioactive wastes, to the use of part-time employees as "sponges" to carry out brief tasks in highly contaminated areas to save regular employees from excessive exposure.

Another lesson discovered recently, he said, was that the nuclear industry had not learnt its lesson. He quoted, for example, advertisements that had been placed in major newspapers by the Edison Electric Institute, claming that the electric companies agreed with the Kemeny Commission's message that nuclear power could proceed, but with caution.

"The Kemeny Commission said no such thing," protested Dr Peterson. "The introduction to our report carefully explains that our assignment limited us to matters bearing directly on the Three Mile Island accident, and that we made no judgements on a number of other issues for example, the disposal of radioactive wastes - that must be considered in deciding whether nuclear power is basically safe."

A different slant on the impact of increased public concern about nuclear hazards was given by Nobel prizewinner Dr
Rosalyn Yalow in the course of a public lecture on radioimmunoassay.

Dr Yalow referred in particular to the recent press coverage that accompanied the decision by various states temporarily to close radioactive waste disposal sites. She suggested that the so-called problem of radioactive waste disposal from hospitals and medical centres was really not a problem but rather a figment of the "small minds and fertile imaginations" of various regulatory agencies.

"An unreasonable fear of any level of radiation associated with radioactivity or nuclear energy generated by newspaper headlines and publicity seekers was now pervasive throughout our society," Dr Yalow said. "Because of this we dissipate research talent and funding on make-work projects in response to unreasonable fears in make-work situations."

She cited, for example, the recent announcement that a number of research groups are to study possible long-range health effects secondary to the reactor accident at Three Mile Island. The maximum estimated dose received by anyone living near the reactor during the accident was bout 70 millirems, less than one third the amount they would have received by spending a year in Colorado.

"If these were the maximal doses received one can predict with absolute certainty that, other than psychological effects, no physical aberration would be demonstrable. Yet we waste time, money and research talent - and generate more psychological stress than would otherwise occur in unnecessary make-work of no scientific merit."

\title{
Women scientists still lose out to men
}

DESPITE almost a decade of affirmative action and raised consciousness, women continue to face a number of barriers in pursuing a scientific career, according to Mrs Betty Vetter, executive director of the Scientific Manpower Commission.

Speaking at a session on employment opportunities for science and engineering doctorates, Mrs Vetter said that women had approximately doubled their share of doctorates in science and engineering since 1970. But they still tended to be employed in lower-paid jobs than men, to have more difficulty in gaining tenure at universities, and to suffer a much higher rate of unemployment.

"It is not at all uncommon to find persons who believe that affirmative action programmes for women or for minorities have given women an edge in employment opportunities, but the statistics do not seem to bear out an assumption of equal treatment, even at the entry level," she said.

For example, while it might be expected that women who obtained their PhDs in the 1950 s and 1960 s had not advanced as rapidly as men from the same cohorts, one might expect to find that those from more recent classes would be advancing at rates comparable to men: yet evidence produced by a survey carried out last year by the National Academy of Sciences showed that this was not true.

In the life sciences, for example, $23 \%$ of academically-employed men earning $\mathrm{PhDs}$ in the period 1970-74 had been appointed assistant professor by 1977 , but only $11 \%$ of women in academic careers earning PhDs in the same period. In contrast, $27.5 \%$ of the women PhDs held the rank of lecturer or instructor, compared to $15.5 \%$ of the men.

In the federal government, a number of studies had shown that women still tend to advance in their careers more slowly than men, overall lagging by an average of $11 / 2$ to 2 civil service grades. For example, in 1978 women made up almost $31 \%$ of all microbiologists employed by the federal government, but their median grade - and their salary average - was about $20 \%$ less than that of their male counterparts.

The best possibility for reducing inequity of opportunity for young women research workers appeared to be in industry. In 1977 , for example, only $10.8 \%$ of all women doctoral scientists and engineers were employed by industry.

Evidence that the general employment prospects for young research scientists and engineers is likely to remain gloomy through most of the 1980 s was presented by Mr Alan Fechter, head of scientific and technical personnel studies for the National Science Foundation.

This situation was created by a number of factors, such as the increased hiring of research workers into non-tenure-track positions, a general reduction of promotion opportunities, declining salaries relative to other sectors, and cutbacks in 2-year and marginal 4-year institutions as a result of falling student enrolments. 